\title{
0671 CALL BACK STUDY INVESTIGATING CHILD DOG BITE INJURY THAT OCCURS IN THE DOMESTIC SETTING IN VICTORIA, AUSTRALIA
}

K Ashby*, E Cassell Correspondence: Monash University Accident Research Centre, Accident Research Centre Building 70 Monash University Victoria 3800, Australia

10.1136/ip.2010.029215.671

Injury surveillance datasets show that over the 3-year period 2005-2007, there were two deaths and at least 511 hospital admissions and 1280 Emergency Departments (ED) presentations for dog bite injury in Victorian children aged 0-14 years. More than two-thirds (69\%) of dog bite injuries occurred in the domestic environment. Surveillance data is focused on the injured child, provides only brief descriptions of the bite event and minimal, if any, information on the dog involved. A 40-60 min telephone interview was conducted with the caregivers of 51 child dog bite victims aged 0-9 recruited through the ED of seven Victorian hospitals (participation rate $67 \%$ ) to investigate potential risk factors for domestic dog bite related to the bite victim, the dog and the home environment in which the bite occurred. A control group of at least 102 children is being recruited from the community. Analysis of case data identified several potential risk factors related to the victim that included: younger age, male gender; advertent and inadvertent provocation of the dog by the child and lack of close supervision of young children. Potential risk factors related to the dog include male sex, having a female owner, lack of obedience training and displaying early and current specific behaviours indicating anxiety, fear and excitability such as frequently being snappy or bitey, aggression over food and fear of thunder, men, strangers and delivery people. Presence of pain due to orthopaedic problems including arthritis also appeared to predispose dogs to biting behaviour. 